\title{
Numerical Investigation of a UCN Source Based on Solid Deuterium by Combining a Simulation Code with an Analytical Approach
}

\author{
Habib Mohammadi', Mohammad Mehdi Firoozabadi ${ }^{1}$, Rouhollah Gheisari² \\ ${ }^{1}$ Department of Physics, University of Birjand, Birjand, Iran \\ ${ }^{2}$ Physics Department, Persian Gulf University, Bushehr, Iran \\ Email: mohammadi@birjand.ac.ir
}

Received 13 September 2014; revised 8 October 2014; accepted 5 November 2014

Copyright (C) 2014 by authors and Scientific Research Publishing Inc.

This work is licensed under the Creative Commons Attribution International License (CC BY). http://creativecommons.org/licenses/by/4.0/

(c) (7)

\begin{abstract}
At thermal ultra-cold neutron (UCN) sources (neutrons in thermal equilibrium with the moderator) only a very small fraction of neutrons have velocities $\sim 6 \mathrm{~m} / \mathrm{s}$. Therefore, the UCN production rate cannot be substantially increased by simply lowering the temperature of the moderator. The new approach is to use the super-thermal principle, i.e., neutrons not in thermal equilibrium with the converter. We want to investigate scattering kernels for a super-thermal UCN source based on a two-layer arrangement of $\mathrm{D}_{2} \mathrm{O}$ and solid $\mathrm{D}_{2}$. The solid $\mathrm{D}_{2}\left(\mathrm{sD}_{2}\right)$ at temperature $8 \mathrm{~K}$ is kept in close contact with $\mathrm{D}_{2} \mathrm{O}$ moderator at room temperature. Using the MCNP code, the fast neutron flux on the spallation target, the thermal flux in the $\mathrm{D}_{2} \mathrm{O}$ near the $\mathrm{sD}_{2}$, and the cold flux in the $\mathrm{sD}_{2}$ are simulated. For a given cold flux, neutron transport equations are calculated. In order to obtain precise neutron scattering kernels, and consequently UCN flux and density, 330 neutron energy groups have been taken. The coupled energy dependent transport equations have been solved by combining MCNPX code with an analytical approach and using implicit method in MATLAB. We have obtained an optimal dimension for the UCN source. A suitable space step has been taken for the numerical stability.
\end{abstract}

\section{Keywords}

Two-Layer UCN Source Based on $\mathrm{D}_{2} \mathrm{O} / \mathrm{sD}_{2}$, Scattering Kernel, Monte Carlo Method, Implicit Method, Super-Thermal Principle 


\section{Introduction}

Ultra-cold neutron (UCN) can be used in fundamental physics experiments, such as neutron electric dipole moment and life-time measurements, which require low velocities and long interaction and observation times [1] [2]. The accuracy of such measurements is limited mainly by statistics [3], and significantly higher UCN densities will allow more tests of the standard model. Several projects have the goal to build new UCN sources in order to provide the required increase in UCN density and flux. Two main source types having the potential to produce substantially higher UCN densities, are based on using either super-fluid helium [4]-[7] or solid deuterium $\left(\mathrm{sD}_{2}\right)$ to down scatter cold neutrons [8] [9]. Basic research to produce experimental UCN converters was done by using $\mathrm{D}_{2}, \mathrm{O}_{2}$, and $\mathrm{CD}_{4}$ [10] [11]. These converters reduce the speed of the cold neutron (CN) to that of UCN. The research works have shown that deuterium can be used in different states of gas, liquid, and solid. The $\mathrm{sD}_{2}$ has more applicants [12] [13]. In UCN sources, CN neutrons have a mean energy of $\sim$ meV. Considerable fractions of these neutrons slow down to $\sim$ neV. We have the goal to study UCN density and flux of a UCN source based on a two-layer arrangement of $\mathrm{D}_{2} \mathrm{O}$ and $\mathrm{sD}_{2}$ by combining MCNPX2.4.0 code with an analytical approach. In Section 2, mathematical tools are presented. The CN flux in the $\mathrm{sD}_{2}$ is simulated with MCNPX code. This result for the CN flux is then used as boundary condition to calculate the UCN flux and density. The results and discussion are presented in Section 3. Finally, the summary and conclusions are given in Section 4.

\section{Material and Methods}

A scheme of the UCN source under consideration is shown in Figure 1. Fast neutrons are produced by a proton beam hitting spallation target. In the heavy water $\left(\mathrm{D}_{2} \mathrm{O}\right)$ moderator at room temperature, the mean kinetic energy of fast neutrons (spallation neutrons) is reduced, and consequently thermal neutrons are produced. Some of the thermal neutrons are cooled and eventually converted to UCN (inside the $\mathrm{sD}_{2}$ ). In Table 1, the proton beam and spallation target parameters have been given as well as UCN source geometry factors, and materials. The $\mathrm{sD}_{2}$ must be almost pure, to reduce up-scattering on para- $\mathrm{D}_{2}$. Here the $\mathrm{sD}_{2}$ layer, with a number density of $N_{0}=3 \times 10^{22} \mathrm{~cm}^{-3}$ and a high ortho-concentration $\left(c_{0}=98.5 \%\right)$, is considered at temperature of $T=8 \mathrm{~K}$ to prevent the dispersion of each UCN. Using the MCNPX code, the fast neutron flux on the target, the thermal

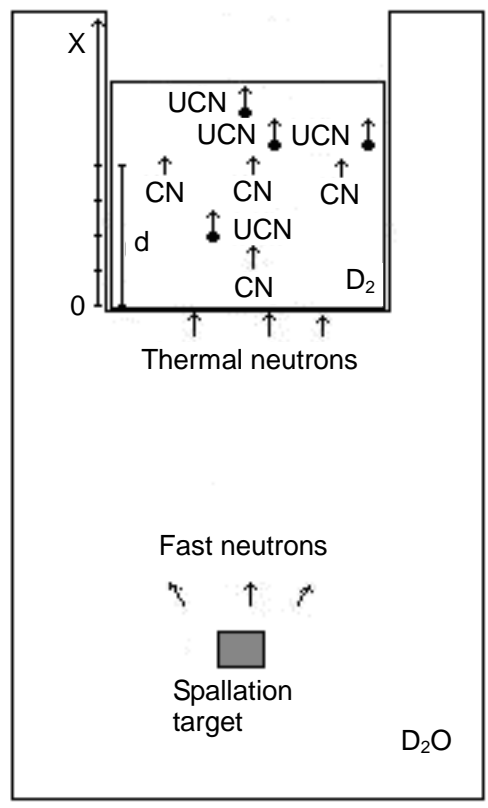

(a)

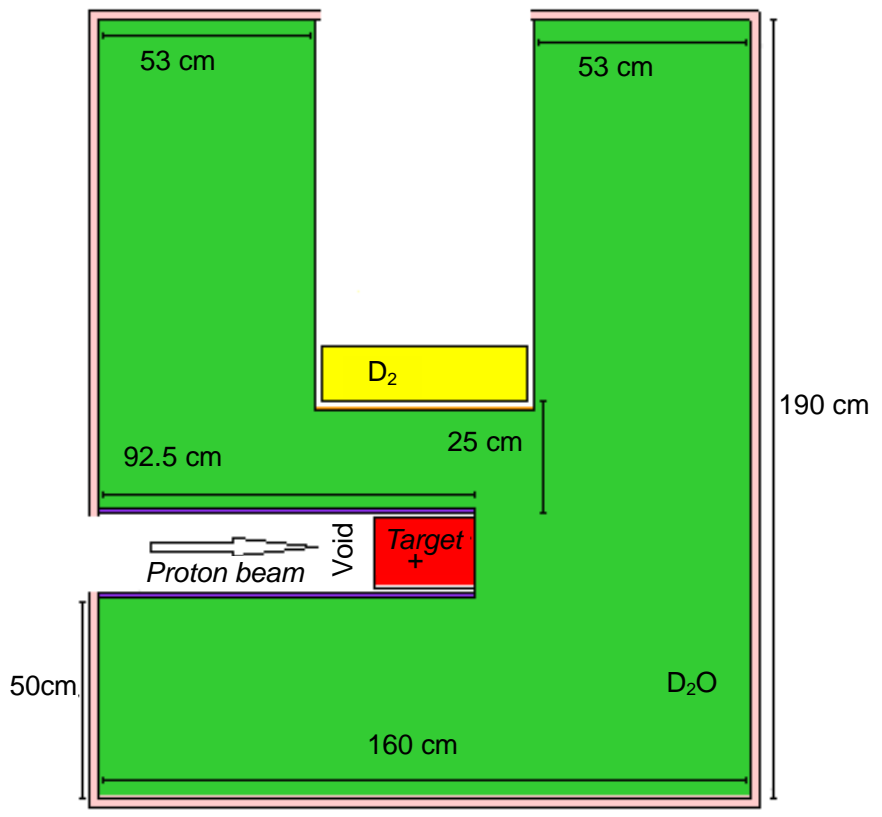

(b)

Figure 1. (a) Schematic drawing of a UCN two-layer arrangement of $\mathrm{D}_{2} \mathrm{O} / \mathrm{sD}_{2}$. The incoming fast neutrons (spallation neutrons) are thermalized in the $\mathrm{D}_{2} \mathrm{O}$ moderator. The thermal neutrons are being transported throughout the $\mathrm{sD}_{2}$ layer, until large fractions of these neutrons are cooled at $d=4 \mathrm{~cm}$. The cold neutrons $(\mathrm{CN})$ are converted to UCN everywhere in the $\mathrm{sD}_{2} . x$ denotes one-dimensional position; (b) Geometric description of the UCN setup used in the MC calculations. 
Table 1. Main description of proton beam, spallation target, UCN source geometry, and material.

\begin{tabular}{|c|c|c|c|c|c|c|c|c|}
\hline $\begin{array}{l}\text { Spallation target } \\
\text { composition }\end{array}$ & Percent (\%) & $\begin{array}{l}\text { Temperature } \\
\text { (K) }\end{array}$ & $\begin{array}{l}\text { Density } \\
\left(\mathrm{g} / \mathrm{cm}^{3}\right)\end{array}$ & $\begin{array}{l}\text { Diameter } \\
\quad(\mathrm{cm})\end{array}$ & $\begin{array}{l}\text { Length } \\
(\mathrm{cm})\end{array}$ & \multicolumn{3}{|c|}{$\begin{array}{l}\text { Neutron source power, } \\
\qquad S_{n}(n / s)\end{array}$} \\
\hline $\mathrm{Pb}$ & 47.8 & & 11.3 & & & & & \\
\hline $\mathrm{Zr}$ & 16.7 & 300 & 6.57 & 17 & 25 & \multicolumn{3}{|c|}{$4.59 \times 10^{16}$} \\
\hline $\mathrm{D}_{2} \mathrm{O}$ & 35.5 & & 1.1 & & & & & \\
\hline Moderator & $\begin{array}{l}\text { Volume } \\
\text { (liters) }\end{array}$ & $\begin{array}{l}\text { Temperature } \\
\text { (K) }\end{array}$ & $\begin{array}{l}\text { Density } \\
\left(\mathrm{g} / \mathrm{cm}^{3}\right)\end{array}$ & $\begin{array}{l}\text { Diameter } \\
\quad(\mathrm{cm})\end{array}$ & $\begin{array}{l}\text { Length } \\
(\mathrm{cm})\end{array}$ & $\begin{array}{l}\text { Shield } \\
\text { material }^{\mathrm{b}}\end{array}$ & \multicolumn{2}{|c|}{$\begin{array}{l}\text { Thickness shield } \\
(\mathrm{cm})\end{array}$} \\
\hline $\mathrm{sD}_{2}$ & $\approx 10^{\mathrm{a}}$ & 8 & 0.199 & 50 & $\approx 5^{\mathrm{a}}$ & $\mathrm{Zr}+$ Steel & $\begin{array}{c}\text { Side wall }^{\mathrm{c}} \\
0.35\end{array}$ & $\begin{array}{c}\text { Surface area } \\
0.05\end{array}$ \\
\hline $\mathrm{D}_{2} \mathrm{O}$ & 3570 & 300 & 1.1 & 160 & 190 & $\mathrm{Al}$ & \multicolumn{2}{|c|}{2} \\
\hline Beam & $\begin{array}{l}\text { Beam diameter } \\
\text { (cm) }\end{array}$ & $\mathrm{E}(\mathrm{MeV})$ & & \multicolumn{2}{|c|}{ Pulse width (s) } & $\begin{array}{l}\text { Shield } \\
\text { material }\end{array}$ & \multicolumn{2}{|c|}{$\begin{array}{l}\text { Thickness shield } \\
\text { (cm) }\end{array}$} \\
\hline Proton & 20 & 590 & & \multicolumn{2}{|c|}{4} & $\mathrm{Al}$ & \multicolumn{2}{|c|}{1} \\
\hline
\end{tabular}

${ }^{\mathrm{a}}$ The optimized length and the corresponding volume (see Table 3); ${ }^{\mathrm{b}}$ The inner and outer side walls have been made from $\mathrm{Zr}$ and Steel, respectively. Here Steel material contains $72 \%{ }^{56} \mathrm{Fe}, 18 \%{ }^{52} \mathrm{Cr}, 8 \%{ }^{58} \mathrm{Ni}$, and $2 \%{ }^{55} \mathrm{Mn}$; ${ }^{\mathrm{c}}$ The thicknesses of the inner side outer side walls equal 0.05 and $0.3 \mathrm{~mm}$, respectively.

flux in the heavy water near the $\mathrm{sD}_{2}$, and the $\mathrm{CN}$ flux in the $\mathrm{sD}_{2}$ are simulated. Cold and thermal neutrons are being transported throughout $\mathrm{sD}_{2}$ and $\mathrm{UCN}$ are being produced everywhere in the $\mathrm{sD}_{2}$. The CN flux increases (versus position $x$ ) and reaches a maximum value at $x=d \cong 4 \mathrm{~cm}$. We assume that these processes can be treated as one-dimension. The CN flux values at $x^{\prime} \leq d$ are used as boundary conditions. We may write the neutron transport equation as follow.

$$
\int_{E_{\min }}^{E_{\max }} \Sigma_{S}\left(E^{\prime} \rightarrow E\right) n\left(E^{\prime}, x\right) v^{\prime} \mathrm{d} E^{\prime}=\left[\Sigma_{S}(E)+\Sigma_{a}(E)\right] n(E, x) v+\langle\cos \theta\rangle v \frac{\partial n(E, x)}{\partial x}
$$

The scattering kernel

$$
\Sigma_{S}\left(E^{\prime} \rightarrow E\right)=N_{0} \sigma_{s}^{\mathrm{UCN}}\left(E^{\prime}\right), \quad 0.3 \leq E^{\prime} \leq 24.1 \mathrm{meV}, \quad E=E_{\mathrm{UCN}}
$$

Is considered for CN neutrons which are directly converted to UCN. We use

$$
\Sigma_{S}\left(E^{\prime} \rightarrow E\right)=N_{0} \frac{\sigma_{s}\left(E^{\prime}\right)}{E^{\prime}(1-\alpha)}, \quad E \leq E^{\prime} \leq E / \alpha, \quad E=E_{\mathrm{CN}}
$$

For description of CN neutrons which slow down and don't fall below about $0.1 \mathrm{meV}$. The definitions of the symbols used in Equations (1)-(3) are:

$x=$ position of $\mathrm{CN}$ or $\mathrm{UCN}$ in $\mathrm{sD}_{2}$

$N_{0} \sigma_{s}^{\mathrm{UCN}}=\mathrm{UCN}$ scattering kernel

$\sigma_{s}^{\mathrm{UCN}}=\mathrm{UCN}$ production cross-section

$\Sigma_{s}=N_{0} \sigma_{s}=$ macroscopic scattering cross-section

$\Sigma_{a}=N_{0} \sigma_{a}=$ macroscopic absorption cross-section

$\sigma_{s}=$ microscopic scattering cross-section

$\sigma_{a}=$ microscopic absorption cross-section

$E^{\prime}=$ initial kinetic energy of neutron

$E=$ final kinetic energy of neutron

$E_{\mathrm{CN}}=$ kinetic energy of each $\mathrm{CN}$

$E_{\mathrm{UCN}}=$ kinetic energy of each UCN

$E_{\text {max }}=$ maximum energy value

$E_{\min }=$ minimum energy value 
$v^{\prime}=$ initial neutron speed

$v=$ final neutron speed

$n(E, x)=$ number density of neutrons with a kinetic energy of $E$ at $x$

$\langle\cos \theta\rangle=$ average cosine of the neutron scattering angle in the laboratory system

$N_{0}=$ number density of $\mathrm{sD}_{2}$

$\alpha=(A-1)^{2} /(A+1)^{2}=$ collision parameter

$A=$ deuteron mass number

When a neutron has low energy, scattering occurs by means of $S$ waves, and hence is only elastic scattering and angular distribution is isotropic with respect to the center of mass system [14]. In the laboratory system, $\langle\cos \theta\rangle$ equals $2 / 3 A$ over the angular region $\theta=0-\pi$. At temperature of $T=8 \mathrm{~K}$, the thermal and para-up scattering contributions are maximal at the lowest neutron energies and there amount to an increase in cross section by $2.5 \%$ [15]. These mean that at such a low temperature CNs lose energy upon elastic scattering and the effects of chemical binding and thermal motion of the scattering nuclei can be ignored. In this way the CN neutron is slowed down until it reaches thermal equilibrium with the $\mathrm{sD}_{2}$ material. On this basis, the scattering kernel given in Equation (3) would be applicable for $T=8 \mathrm{~K}$. This scattering kernel for a neutron scattering from a completely free nucleus was first shown by Fermi. To numerically solve Equation (1) using algebraic equations, the spatial and energy variables must be discretized. We replace the space derivative by a first order backward difference approximant at position $x_{i}$. Substituting Equation (3) into Equation (1) and after the spatial and energy discretization of Equation (1), we obtain the following recurrence equations.

$$
\begin{aligned}
& \frac{a_{g}}{h} n^{i+1, g}\left(E_{g}\right)+\left(b_{g}-\frac{f_{g}}{h}\right) n^{i, g}\left(E_{g}\right)-\sum_{g^{\prime}=g}^{g_{\max }^{\prime}} c_{g^{\prime}, g^{\prime}+1} n^{i, g^{\prime}}\left(E_{g^{\prime}}\right)=0, \\
& g=1,2, \cdots, 120, \quad g_{\max }^{\prime}=10 g-1 \quad(g \leq 12), \\
& g_{\max }^{\prime}=120 \quad(g>12) .
\end{aligned}
$$

Substituting Equation (2) into Equation (1) and after discretization we obtain the following algebraic equations.

$$
\frac{e_{k}}{h} n^{i+1, k}\left(E_{k}\right)+\left(p_{k}-\frac{q_{k}}{h}\right) n^{i, k}\left(E_{k}\right)-\sum_{g=1}^{120} A_{g} n^{i, g}\left(E_{g}\right)=0, \quad k=1,2, \cdots, 210
$$

$n^{i, g}\left(E_{g}\right)$ and $n^{i+1, k}\left(E_{k}\right)$ represent the numerical densities of CN and UCN with kinetic energies $E_{g}$ and $E_{k}$ ( $g$ and $k$ energy groups) at $x_{i}$, respectively. $h$ represents a space step. Energy variables have typically been discretized by the multi-group model [14], where each energy group represents one constant energy. In our calculations, the parameters $a_{g}, b_{g}, c_{g}, f_{g}, e_{k}, p_{k}, q_{k}$, and $A_{g}$ are defined and are the constants for a given energy group:

$$
\begin{gathered}
a_{g}=f_{g}=\frac{v_{g}}{3}, \quad v_{g}=1.383 \times 10^{6} \sqrt{E_{g}(\mathrm{eV})} \mathrm{cm} / \mathrm{s} . \\
b_{g}=\left[\Sigma_{a}\left(E_{g}\right)+\Sigma_{s}\left(E_{g}\right)\right] v_{g} . \\
c_{g^{\prime}, g^{\prime}+1}=\bar{\Sigma}_{s} \int_{E_{g^{\prime}}}^{E_{g^{\prime}+1}} \frac{v^{\prime}\left(E^{\prime}\right)}{E^{\prime}(1-\alpha)} \mathrm{d} E^{\prime}, \quad \bar{\Sigma}_{s}=\Sigma_{s}\left(\frac{E_{g^{\prime}}+E_{g^{\prime}+1}}{2}\right) . \\
e_{k}=q_{k}=\frac{v_{k}}{3}, \quad v_{k}=1.383 \times 10^{6} \sqrt{E_{k}(\mathrm{eV})} \mathrm{cm} / \mathrm{s} . \\
A_{g}=0.2 N_{0} \sigma_{s}^{\mathrm{UCN}}\left(E_{g}\right) \bar{v}_{g, g+1}, \quad \bar{v}_{g, g+1}=\frac{v_{g}+v_{g+1}}{2} .
\end{gathered}
$$


For solving Equations (4) and (5) we take the energy difference between each two neighboring energy groups as

$$
E_{g+1}-E_{g}=0.2 \mathrm{meV}, \quad E_{k+1}-E_{k}=1 \mathrm{neV}
$$

The boundary condition is as follow:

$$
n\left(E_{\mathrm{CN}}, x^{\prime}\right)=S_{n} \frac{f\left(x^{\prime}, E_{\mathrm{CN}}\right)}{v_{\mathrm{CN}}}, \quad S_{n} \int f\left(x^{\prime}, E_{\mathrm{CN}}\right) \mathrm{d} E_{\mathrm{CN}}=\phi_{\mathrm{CN}}\left(x^{\prime}\right)
$$

The $f\left(E_{\mathrm{CN}}, x^{\prime}\right)$ is CN energy spectrum at $x^{\prime}$, and $S_{n}$, in units of $\mathrm{s}^{-1}$, is the neutron source power. The notation $\phi_{\mathrm{CN}}$, in units of $\mathrm{cm}^{-2} \cdot \mathrm{s}^{-1}$, represents the $\mathrm{CN}$ flux (integrated over $E_{\mathrm{CN}}=0.3-24.1 \mathrm{meV}$ ) which strongly depends on the proton beam current. Using the MCNPX code, the fast flux on the target, the thermal flux in the $\mathrm{D}_{2} \mathrm{O}$ near the $\mathrm{sD}_{2}$, and the $\mathrm{CN}$ flux in the $\mathrm{sD}_{2}$ are simulated. The Monte Carlo (MC) calculations are based on the neutron cross sections of $\mathrm{Pb}, \mathrm{Zr}, \mathrm{Al}, \mathrm{D}_{2} \mathrm{O}$, Steel at $300 \mathrm{~K}, \mathrm{sD}_{2}$ at $8 \mathrm{~K}$. These cross-sections have been calculated using the nuclear data processing program NJOY [16]. The algebraic Equations (4) and (5) are solved by a backward implicit method in MATLAB. These cross-section values have been extracted from literature data [12] [15] [17]-[19].

\section{Results and Discussion}

We have considered a UCN two-layer source of $\mathrm{D}_{2} \mathrm{O} / \mathrm{sD}_{2}$ and calculated its UCN yield. In the $\mathrm{D}_{2} \mathrm{O}$ moderator the incoming fast neutrons (spallation neutrons) slow down to thermal region at room temperature. They decelerate in the $\mathrm{sD}_{2}$ fairly and have a velocity distribution in the energy range of $E_{\mathrm{CN}}=0.3-24.1 \mathrm{meV}$. Using the MCNPX code, the average fast flux on the target, the thermal flux in the $\mathrm{D}_{2} \mathrm{O}$ near the $\mathrm{sD}_{2}$ layer, and the $\mathrm{CN}$ flux in the $\mathrm{sD}_{2}$ have been calculated, as given in Table 2. The spallation target produces the fast neutron flux $\phi_{\text {fast }}=5 \times 10^{14} \mathrm{~cm}^{-2} \cdot \mathrm{s}^{-1}$. The produced thermal neutrons penetrate the $\mathrm{sD}_{2}$ with the flux $\phi_{\text {th }}=3.69 \times 10^{13} \mathrm{~cm}^{-2} \cdot \mathrm{s}^{-1}$, until large fractions of them are cooled at $x=d=4 \mathrm{~cm}$. Substituting $f\left(E_{\mathrm{CN}}, x^{\prime}\right)$ into Equation (13) and taking it as the boundary condition, the evolution in space $(x>0)$ of UCN and CN has been calculated with solving the coupled transport equations in MATLAB. In order to calculate UCN density and flux, 330 neutron energy groups have been considered. UCNs emerge from a layer (with a thickness about $d=4 \mathrm{~cm}$ ) near the $\mathrm{sD}_{2}$ surface area so it is only this layer that needs to be integrated over. By this integration, the UCN flux versus $x$ is shown in Figure 2. The UCN production rate versus $x$ is shown in Figure 3. In Figure 2 and Figure 3 the data points are for UCNs in the energy range of $40-250 \mathrm{neV}$. In the present multi-group calculations, a converge result has been achieved with a suitable space step. The space step $h$ has been determined to be about $0.1 \mathrm{~cm}$. In Table 3, the numerical results of UCN production have been presented for different sizes of the $\mathrm{sD}_{2}$. In the same table, our results of the average UCN production rate and density have been compared with those of the PSI UCN source [20] [21].

Table 2. The simulation results of the neutron flux $\left(\mathrm{cm}^{-2} \cdot \mathrm{s}^{-1}\right)$.

\begin{tabular}{cc}
\hline Depth $(\mathrm{cm})^{\mathrm{a}}$ & Cold flux in the $\mathrm{sD}_{2}$ \\
\hline 1.0 & $2.94 \times 10^{13}$ \\
2.0 & $3.31 \times 10^{13}$ \\
3.0 & $3.51 \times 10^{13}$ \\
4.0 & $3.61 \times 10^{13}$ \\
5.0 & $3.60 \times 10^{13}$ \\
6.0 & $3.54 \times 10^{13}$ \\
7.0 & $3.41 \times 10^{13}$ \\
8.0 & $3.15 \times 10^{13}$ \\
\hline
\end{tabular}

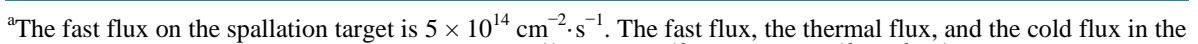
$\mathrm{D}_{2} \mathrm{O}$ near the $\mathrm{sD}_{2}$ approximately equal to $2.12 \times 10^{11}, 3.69 \times 10^{13}$ and $1.73 \times 10^{13} \mathrm{~cm}^{-2} \cdot \mathrm{s}^{-1}$, respectively. 


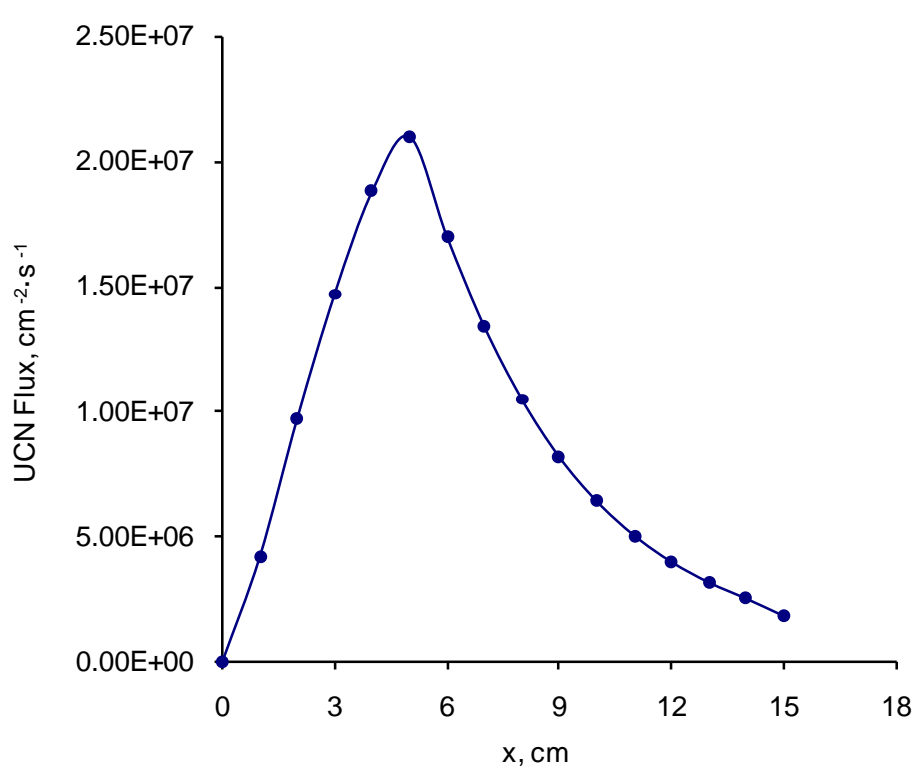

Figure 2. UCN flux versus thickness $x$ of the $\mathrm{sD}_{2}$ (see Figure $1(\mathrm{a})$ ). The curve reaches to a maximum at $x=4.3 \mathrm{~cm}$. Data points represent UCNs in the energy range of $40-250 \mathrm{neV}$.

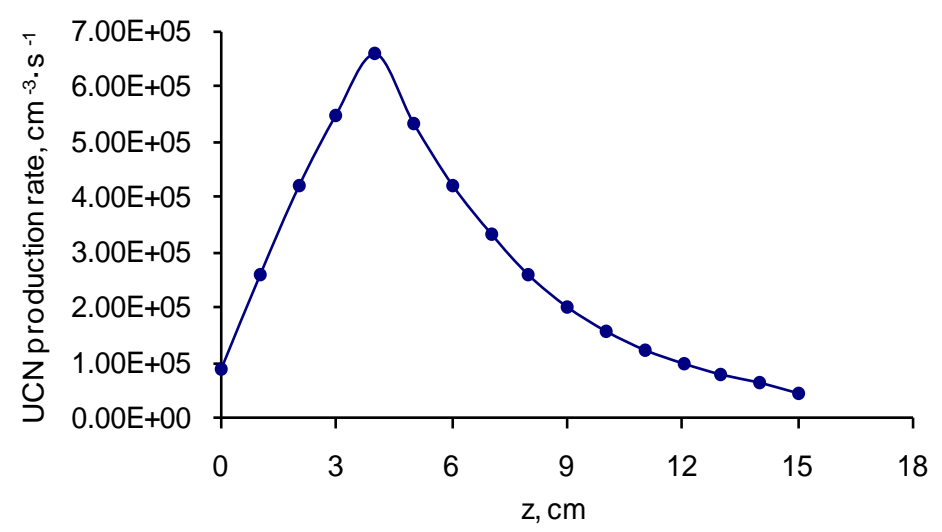

Figure 3. UCN production rate versus thickness $x$ of the $\mathrm{sD}_{2}$ (see Figure $1($ a)). The curve reaches to a maximum at $x \approx 4 \mathrm{~cm}$. Data points represent UCNs in the energy range of $40-250 \mathrm{neV}$.

\section{Summary and Conclusions}

In the present work, a UCN source based on $\mathrm{D}_{2} \mathrm{O} / \mathrm{sD}_{2}$ has been studied. The $\mathrm{sD}_{2}$ at $8 \mathrm{~K}$ is kept in close contact with the $\mathrm{D}_{2} \mathrm{O}$ moderator at room temperature. The $\mathrm{sD}_{2}$ layer, with a number density of $N_{0}=3 \times 10^{22} \mathrm{~cm}^{-3}$ and a high ortho-concentration $\left(c_{0}=98.5 \%\right)$, has been considered at temperature of $T=8 \mathrm{~K}$. Using the MCNPX code, the fast flux on the spallation target, the thermal flux in the $\mathrm{D}_{2} \mathrm{O}$ near the $\mathrm{sD}_{2}$, and the $\mathrm{CN}$ flux in the $\mathrm{sD}_{2}$ have been simulated. Geometric description of the UCN setup has been shown in Figure 1. The simulation results of the neutron flux have been given in Table 2. The penetration depth $d$, where thermal neutrons are transformed fairly into $\mathrm{CN}$ neutrons, approximately equals $4 \mathrm{~cm}$. This distance may correspond to the scattering mean-free path of thermal neutrons. By the reason of no ultra-cold scattering cross-sections in input files of MCNP code, it cannot be used to continually model scattering down to neV energies. By considering simulated CN spectrums as boundary conditions, the UCN flux and the corresponding production rate in the $\mathrm{sD}_{2}$ have been investigated by multi-group model (330 neutron energy groups) and using a backward implicit method. Once CN kinetic energy changes from $9 \mathrm{meV}$ to $\approx 9.7 \mathrm{meV}, \sigma_{s}^{\mathrm{UCN}}$ falls rapidly. On this basis, we have selected the energy interval $E_{g+1}-E_{g}=0.2 \mathrm{meV}$. The space step $0.1 \mathrm{~cm}$ has been taken in our calculations. It may be worth men- 
Table 3. The numerical results of average UCN flux, density and production in the $\mathrm{sD}_{2}{ }^{\mathrm{a}}$.

\begin{tabular}{ccccc}
\hline Length $(\mathrm{cm})$ & $\begin{array}{c}\text { Volume } \\
\text { (liters) }\end{array}$ & $\begin{array}{c}\text { Average UCN flux } \\
\left(\mathrm{cm}^{-2} \cdot \mathrm{s}^{-1}\right)\end{array}$ & $\begin{array}{c}\text { Average UCN production rate } \\
\left(\mathrm{cm}^{-3} \cdot \mathrm{s}^{-1}\right)\end{array}$ & $\begin{array}{c}\text { Average UCN density } \\
\left(\mathrm{cm}^{-3}\right)\end{array}$ \\
\hline 1.0 & 1.963 & $4.44 \mathrm{e}+6$ & $1.28 \mathrm{e}+5$ & 2777 \\
2.0 & 3.926 & $7.66 \mathrm{e}+6$ & $1.48 \mathrm{e}+5$ & 3211 \\
3.0 & 5.889 & $1.04 \mathrm{e}+7$ & $1.62 \mathrm{e}+5$ & 3515 \\
4.0 & 7.852 & $1.23 \mathrm{e}+7$ & $1.71 \mathrm{e}+5$ & 3710 \\
5.0 & 9.815 & $1.69 \mathrm{e}+7$ & $1.89 \mathrm{e}+5$ & 4101 \\
6.0 & 11.616 & $1.61 \mathrm{e}+7$ & $1.88 \mathrm{e}+5$ & 4079 \\
7.0 & 13.741 & $1.52 \mathrm{e}+7$ & $1.87 \mathrm{e}+5$ & 4057 \\
8.0 & 15.704 & $1.43 \mathrm{e}+7$ & $1.86 \mathrm{e}+5$ & 4036 \\
9.0 & 17.667 & $1.36 \mathrm{e}+7$ & $1.85 \mathrm{e}+5$ & 4014 \\
10.0 & 19.630 & $1.29 \mathrm{e}+7$ & $1.84 \mathrm{e}+5$ & 3993 \\
11.0 & 21.593 & $1.24 \mathrm{e}+7$ & $1.82 \mathrm{e}+5$ & 3949 \\
12.0 & 23.556 & $1.18 \mathrm{e}+7$ & $1.80 \mathrm{e}+5$ & 3906 \\
13.0 & 25.519 & $1.14 \mathrm{e}+7$ & $1.78 \mathrm{e}+5$ & 3862 \\
14.0 & 27.482 & $1.10 \mathrm{e}+7$ & $1.76 \mathrm{e}+5$ & 3819 \\
15.0 & 29.445 & $1.06 \mathrm{e}+7$ & $1.73 \mathrm{e}+5$ & 3754
\end{tabular}

${ }^{\mathrm{a}}$ The calculations have been performed without taking temperature increase; ${ }^{\mathrm{b}}$ At PSI, the UCN production rate is expected to be $2.9 \times 10^{5} \mathrm{~cm}{ }^{-3} \cdot \mathrm{s}^{-1}$. The volume of $\mathrm{sD}_{2}$ is disk shaped (with 27 liters in volume and $50 \mathrm{~cm}$ in diameter) [20] [21].

tioning that this value is smaller than $\lambda_{s} / 10$. Here $\lambda_{s}$ denotes the $\mathrm{CN}$ scattering mean-free path in the $\mathrm{sD}_{2}$. The UCN flux and the corresponding production rate (versus position $x$ ) have been given in Figure 2 and Figure 3, respectively. The numerical results of average UCN flux, UCN production rate and density have been shown in Table 3. The results have been presented without taking temperature increase. In fact, the limiting UCN density is strongly dependent on the heat load on the moderator and UCN life-time $\left(\tau_{\text {ucn }}\right)$ in the $\mathrm{sD}_{2}$. For instance, consider $\approx 27$ liters of $\mathrm{sD}_{2}$ and assume a heat load of $0.4 \mathrm{W \mu A} \mathrm{A}^{-1}$. The power density will be $\approx 76$ $\mathrm{mWg}^{-1} \cdot \mathrm{mA}^{-1}$ [22]. During a $4 \mathrm{~s}$ long proton beam pulse, the temperature rises from 8 to $9.7 \mathrm{~K}$, and consequently the UCN density reaches about $63.1 \%$ of the maximum value. $\tau_{\text {ucn }}$ may be determined by

$$
\tau_{\mathrm{ucn}}^{-1}=\tau_{a}^{-1}+\tau_{\text {para }}^{-1}+\tau_{\text {phonon }}^{-1} .
$$

Here, $\tau_{a}=\frac{1}{N_{0} \sigma_{a} v_{\mathrm{UCN}}}=150 \mathrm{~ms}$ is the nuclear absorption time; $\tau_{\text {para }}=\frac{1}{N_{0}\left(1-c_{0}\right) \sigma_{\text {para }} v_{\mathrm{UCN}}}=100 \mathrm{~ms}$ is the para up-scattering time; and $\tau_{\text {phonon }}=\frac{1}{N_{0} \sigma_{\text {up }}(T) v_{\text {UCN }}} \cong 34 \mathrm{~ms}$ is the thermal up-scattering time. Here $\sigma_{\text {para }}$ and $\sigma_{\text {up }}$ denote para and thermal up-scattering cross-sections, respectively [17] [19]. Taking such a long pulse and $\tau_{\text {ucn }}$ about $21.7 \mathrm{~ms}$, the UCN density approximately equals $2406 \mathrm{~cm}^{-3}$. However, owing to the good thermal conductivity of $\mathrm{sD}_{2}$, its temperature may be kept at the level of $8 \mathrm{~K}$ by liquid helium cooling [8]. As shown in Table 3, we have obtained an optimal length for the UCN source. The optimal thickness of the $\mathrm{sD}_{2}$ is about 5 $\mathrm{cm}$, where average UCN density reaches to a maximum value. UCNs with speeds of 2.39 and $6.91 \mathrm{~m} / \mathrm{s}$, which correspond to UCN minimum and maximum energies, travel 5.18 and $15 \mathrm{~cm}$ in $21.7 \mathrm{~ms}$, respectively. These distances are greater than the optimal length of the $\mathrm{sD}_{2}$. The $\mathrm{CN}$ flux values have been provided with acceptable accuracy, mostly below $2.6 \%$, by MCNPX code. In this work, the errors are mainly due to the assumptions made in the calculations of $\eta$ and $c_{g^{\prime}, g^{\prime}+1}$. We expect the effects that 1) slowing down of thermal neutrons at larger depths $(x>4 \mathrm{~cm})$ gives an enhancement; 2) variations of neutron scattering angle and effect of thermal motion 
of the scattering nuclei give a reduction in the values from our model. We recommend to consider these effects for calculations of precise values of $\eta$ and $c_{g^{\prime}, g^{\prime}+1}$. The problem was treated as one-dimension by the two reasons: 1 ) the mean square root of the $\mathrm{sD}_{2}$ surface area is larger than average distance a $\mathrm{CN}$ neutron travels along its path before being converted; 2) UCNs emerge from a layer (with a thickness about $d=4 \mathrm{~cm}$ ) near the $\mathrm{sD}_{2}$ surface area. The accuracy of the results can increase when the geometry of the $\mathrm{sD}_{2}$ is considered using three-dimensional transport equation. The third author is planning to produce a unified code which can combine the CN flux modeling with UCN production and loss.

\section{Acknowledgements}

The authors wish to thank Birjand University, Birjand, Iran, for their support.

\section{References}

[1] Ignatovich, V.K. (1990) Ultracold Neutrons. Clarendon Press, Oxford.

[2] Golub, R., Richardson, D.J. and Lamoreaux, S.K. (1991) Ultra-Cold Neutrons. Hilger, Bristol.

[3] Steyerl, A., et al. (1986) Physics Letters A, 116, 347. http://dx.doi.org/10.1016/0375-9601(86)90587-6

[4] Golub, R. and Pendlebury, J.M. (1977) Physics Letters A, 62, 337. http://dx.doi.org/10.1016/0375-9601(77)90434-0

[5] Brome, C.R., Butterworth, J.S., Dzhosyuk, S.N., Mattoni, C.E.H., McKinsey, D.N., et al. (2001) Physical Review C, 63, Article ID: 055502. http://dx.doi.org/10.1103/PhysRevC.63.055502

[6] Masuda, Y., Kitagaki, T., Hatanaka, K., Higuchi, M., Ishimoto, S., et al. (2002) Physical Review Letters, 89, Article ID: 284801. http://dx.doi.org/10.1103/PhysRevLett.89.284801

[7] Zimmer, O., Baumann, K., Fertl, M., Franke, B., Mironov, S., et al. (2007) Physical Review Letters, 99, Article ID: 104801. http://dx.doi.org/10.1103/PhysRevLett.99.104801

[8] Serebrov, A.P. (2000) Nuclear Instruments and Methods in Physics Research Section A, 440, 653. http://dx.doi.org/10.1016/S0168-9002(99)01057-8

[9] Saunders, A., Anaya, J.M., Bowles, T.J., Filippone, B.W., Geltenbort, P., et al. (2004) Physics Letters B, $593,55$. http://dx.doi.org/10.1016/j.physletb.2004.04.048

[10] Atchison, F., Blau, B., Bodek, K., Van den Brandt, B., Brys, T., et al. (2009) Nuclear Instruments and Methods in Physics Research Section A, 611, 252. http://dx.doi.org/10.1016/j.nima.2009.07.072

[11] Frei, A., Gutsmiedl, E., Morkel, C., Muller, A.R., Paul, S. and Urban, M. (2009) Physical Review B, 80, Article ID: 064301. http://dx.doi.org/10.1103/PhysRevB.80.064301

[12] Atchsion, F., Blau, B., Bodek, K., Van den Brandt, B., Brys, T. and Fierlinger, P. (2007) Physical Review Letters, 99, Article ID: 262502. http://dx.doi.org/10.1103/PhysRevLett.99.262502

[13] Altarev, I., Daum, M., Frei, A., Gutsmiedl, E., Hampel, G., Hartmann, F.J., et al. (2008) The European Physical Journal A, 37, 9-14. http://dx.doi.org/10.1140/epja/i2008-10604-8

[14] Sekimoto, H. (2007) Nuclear Reactor Theory. Tokyo Institute of Technology Press, Tokyo.

[15] Atchsion, F., Blau, B., Bodek, K., Van den Brandt, B., Brys, T., Fierlinger, P., et al. (2005) Physical Review Letters, 95, Article ID: 182502. http://dx.doi.org/10.1103/PhysRevLett.95.182502

[16] MacFarlane, R.E. and Muir, D.W. (1994) The NJOY Nuclear Data Processing Systems Version 91, LA-12740-M. Los Alamos National Laboratory, Los Alamos.

[17] Kasprzak, M. (2004) Thermal Up-Scattering of Very Cold and Ultra-Cold Neutrons in Solid Deuterium. Master's Thesis, Jagiellonian University Press, Krakow.

[18] Frei, A., Gutsmiedl, E., Morkel, C., Muller, A.R., Paul, S., Rols, S., et al. (2010) Europhysics Letters, 92, Article ID: 62001. http://dx.doi.org/10.1209/0295-5075/92/62001

[19] Kasprzak, M. (2008) Ultra-Cold Neutron Converters. Ph.D. Thesis, University of Vienna, Vienna.

[20] Atchsion, F., Van den Brandt, B., Brys, T., Fierlinger, P., Hautle, P., Henneck, R., et al. (2005) Physical Review C, 71, Article ID: 054601. http://dx.doi.org/10.1103/PhysRevC.71.054601

[21] The PSI UCN Website: http://ucn.web.psi.ch/

[22] Atchison, F. (2002) Internal Report, TM-14-02-02, Part I and II. 
Scientific Research Publishing (SCIRP) is one of the largest Open Access journal publishers. It is currently publishing more than 200 open access, online, peer-reviewed journals covering a wide range of academic disciplines. SCIRP serves the worldwide academic communities and contributes to the progress and application of science with its publication.

Other selected journals from SCIRP are listed as below. Submit your manuscript to us via either submit@scirp.org or Online Submission Portal.
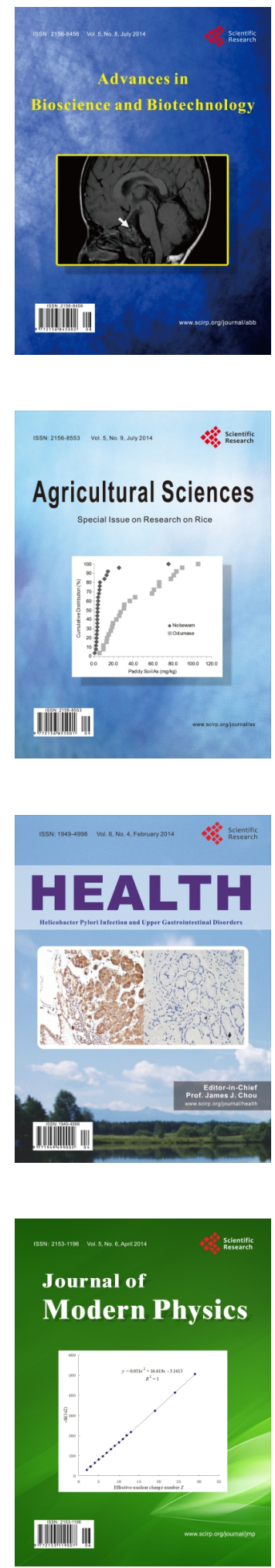
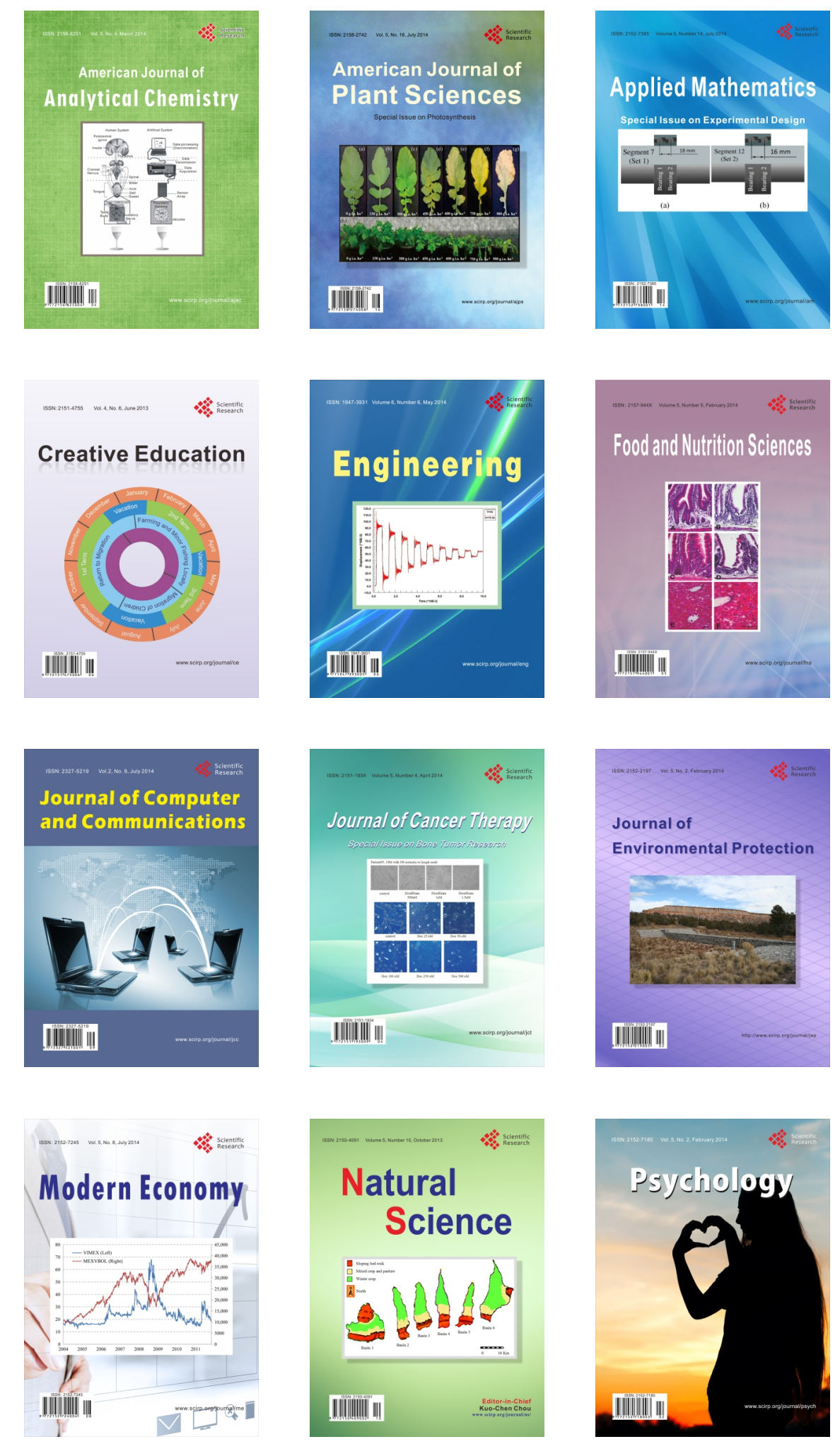